Autopsy confirmed evidence of CJD.

Initial EEG showed periodic diphasic complexes predominantly in the left hemisphere; they occurred every 1000 milliseconds and disappeared during sleep. Several weeks later, BPC became generalised but the relation to sleep - wake cycles could not be determined because of vegetative state.

The pathogenesis of BPC in CJD is unknown but several hypotheses have been proposed. Traub and Pedley ${ }^{3}$ proposed that fusion of dendritic processes may lead to electrotonic coupling between neurons and this in turn might lead to large aggregates of cells, firing synchronously to produce BPC. They suggested that breaks in the neuronal and dendritic membrane, which have been shown to occur in CJD, ${ }^{4}$ might lead to electrotonic coupling. They also argued that the cerebral cortical origin of BPC in CJD is supported by the lack of BPC in Kuru, a disorder in which spongiform changes occur mainly in the cerebellum and brain stem. ${ }^{5}$ Szirmai et al ${ }^{6}$ studied a single patient in whom diazepam produced suppression of BPC and proposed that the drug depressed the rhythmicity of a deep thalamic pacemaker responsible for BPC in CJD. Similar findings with diazepam and methylphenidate were subsequently reported in another patient by Rossini et $\mathrm{al}^{7}$ and these workers hypothesized that lack of intracortical inhibition produced BPC. Our present findings in 3 additional cases suggest that mechanisms involved in the production of BPC in CJD are also linked to the reticular activating system and its diffuse cortical projection fibers.

M.B.M. Sundaram

Dept. of Neurological Sciences University of Saskatchewan

Saskatoon. Canada

G.B. Young

Dept. of Neurological Sciences University of Western Ontario London, Canada

1. Kuroiwa Y, Celesia G. Clinical significance of periodic EEG palterns. Arch Neurol 1980; 37: 15-20.

2. Volavka J, James B, Reker D, Pollock V, Cho D. Electroencephalographic and other effects of naloxone in normal man. Life Sci 1979; 25: 1267-1272.

3. Traub RD, Pedley TA. Virus-induced electrotonic coupling: Hypothesis on the mechanism of periodic EEG discharges in Creutzfeldt-Jakob disease. Ann Neurol 1981; 10:405-410.

4. Lampert PW, Gajdusek DC, Gibbs CJ Jr. Pathology of dendrites in subacute spongiform virus encephalopathies. In Kreutzberg GW (Ed): Physiology and Pathology of Dendrites. New York. Adv Neurol 1975; 12: 465-470.

5. Klatzo I. Gajdusek DC, Zigas V. Pathology of Kuru. Lab Invest 1969; 8: 799-847.

6. Szirmai I, Guseo A. Czopf J, Palffy G. Analysis of clinical and electrophysiological finding in Jakob Creutzfeldt disease. Arch Psychiatr Nervenkr 1976; 222: 315-323.

7. Roosini PM, Caltagirone C, David P, Macchi G. Jakob Creutzfeldt disease: Analysis of EEG and evoked potentials under basal conditions and neuroactive drugs. Eur Neurol 1979; 18: 269279.

\section{YOUNG AGE PARKINSONISM AND COMMON DRUGS}

\section{To the Editor:}

Secondary parkinsonism can be a complication of a wide variety of chemical and metabolic insults.
Six young patients with parkinsonism, seen in the past five years, who had taken large amounts of common prescription or proprietary drugs are reported. In the same time only one female, age 42 , with the disease and no drug history has been seen. If these observations are not unique there may be a causal relationship between these substances and the disease and the purpose of this letter is to raise this possibility.

Patient 1: A female bank teller, aged 25, began taking a dextroamphetamine anorexiant, tablet size unknown, three to four times a day. for the next six years and then replaced it with diethylpropion (Tenuate ${ }^{\circledR}$ ) for the next three years with simultaneous daily diazepam, dose unknown. All drugs were stopped in 1975. In 1986 (age 43) she developed left hemiparkinsonism followed by some parkinsonian facial features and rigidity of both legs. She responded well to antiparkinsonian medication.

Patient 2: A female administrative assistant born in 1947 became sensitive to housedust and pollen in 1957. Each spring and summer for the next 10 years she used xylometazoline $\mathrm{HCl}$ nosedrops (Otrivin ${ }^{(\mathbb{B})}$ and spray for nasal congestion and hayfever. Chlorpheniramine (ChlorTripolon $\left.{ }^{(}\right)$was also used. In 1963 a dextro-amphetamine anorexiant (dose unknown) was taken daily until 1973 when all medications were stopped. In 1983 a right-sided resting tremor of the hand and arm began and by 1986 the tremor involved the right leg and there was awkwardness and dragging of the leg. Physical examination revealed asymmetrical generalised parkinsonism.

Patient 3: A company manager, born in 1930, became an alcoholic in 1948 and continued drinking until 1972. Since then he has continually used xylometazoline $\mathrm{HCl}$ (Otrivin ${ }^{\circledR}$ ) as a nasal spray several times a day. A $20 \mathrm{ml}$ spray bottle lasts approximately one week. In 1983 the right hand became tremulous and in 1985 a diagnosis of right hemiparkinsonism was made. Appropriate investigations were normal and various combinations of antiparkinsonian medications were ineffective. He continues the daily use of the nasal spray.

Patient 4: A female clerk-typist, born in 1950, suffered from frequent, severe, migraine headaches. In 1979 she was started on a combination of acetylsalicylic acid, caffeine, butabarbital, plus $30 \mathrm{mgms}$ of codeine (Fiornal ${ }^{\circledR}$ ). She took four to 10 per day plus acetaminophen with $15 \mathrm{mgms}$ of codeine, 40-60 tablets per day for the next four or five years. There were sporadic additions of diazepam $2-5 \mathrm{mgms}$, three or four per day, and regular daily dimenhydrinate $\left(\mathrm{Gravol}^{\circledR}\right)$ 150-180 mgms per day for nausea and large amounts of cascara for constipation. All medications were stopped in 1984. In 1986 she complained of a progressive limp due to weakness and stiffness of the left leg and six months later found her typing abnormal. Examination revealed predominantly left-sided parkinsonism that responded to levodopa-carbidopa medication and enabled her to return to work with good typing skills and marked general improvement. She has remained well with no change in symptoms or medication since then.

Patient 5: A male high school teacher, born in 1945. complained of weakness and dragging of the left leg in 1986. By the end of 1987 generalised signs of parkinsonism were evident. He had taken acetaminophen 300 to $600 \mathrm{mgms}$ for insomnia for the past 20 years and had combined this with diphenhydramine (Sominex ${ }^{\circledR}$ ) $20 \mathrm{mgms}$ per day from 1976 to 1986 . The response to antiparkinsonian medication was poor. He continues with the nightly medications.

Patient 6: A male machinist, born in 1934, developed a chronic E. Coli urinary tract infection in 1977. This was treated with trimethoprim-sulfamethoxazole (Septra ${ }^{\circledR}$ ) half a tablet twice a day until 1984. He then became aware of a fine resting tremor in the left thumb and some left hand loss of dexterity and seborrheic scaling on the left side of the face. Idiopathic parkinsonism was assumed to be the diagnosis and not treated at his request. A year later the urinary tract symptoms recurred, the trimethoprim-sulphamethoxazole was replaced with norfloxacin which was effective. Within three months the tremor and left hand clumsiness had disappeared and the seborrheic crusting was no longer evident. Eighteen months later there is no evidence of urinary tract infection or parkinsonism.

There may be no relationship between the parkinsonism of these six patients and these common drugs. However, the 
parkinsonism began at an unusually early age and each of these drugs has some known effect on catecholamine metabolism. Some of them have been used as adjunctive antiparkinsonian therapy and as indicated by Klawans, medications used to treat parkinsonism, may paradoxically, cause or worsen the disease. ${ }^{1}$

Three of the patients (\#2, 4 and 5) had taken antihistamines alone or in combination, either an alkylamine or an ethanolamine. Oral facial dyskinesia with prolonged use of alkylamine antihistamines has been reported in two patients. ${ }^{2}$ Both had reduced homovanillic acid accumulation induced by probenecid loading suggesting a functional or organic upset of central dopamine pathways. The structural and pharmacological similarities between some antihistamines and the phenothiazines suggest that the former may produce dyskinesia and possibly parkinsonism if used over a long enough time. Three patients used sympathomimetic amines. The stimulants, methylphenidate $\left(\right.$ Ritalin $^{\circledR}$ ), dextro-amphetamine, and pemoline are known to cause movement disorders (tics, chorea) and worsen tardive dyskinesiae. Although methylphenidate and amphetamine increase presynaptic dopamine release they also block the re-uptake of catecholamines. ${ }^{3}$ Amphetamine releases norepinephrine from central noradrenergic neurons and epinephrine increases rigidity and tremor in Parkinson's disease. ${ }^{4}$ Spector et al ${ }^{5}$ have shown (guinea pig) that increased brain norepinephrine inhibits tyrosine conversion at the hydroxylase level, thus blocking the initial step of catecholamine metabolism.

Patient 6 took only trimethoprim-sulfamethozazole, daily for seven years. His parkinsonism disappeared when he stopped the medication and has not returned after two years. Trimethoprim selectively inhibits bacterial dihydrofolate reductase. Whether the antibiotic can selectively interfere with amine metabolism in the basal ganglia is unknown.

The long interval between cessation of the drugs and onset of symptoms ( 11,10 and 2 years) in three of the patients is unexplained although not unknown. They may have idiopathic Parkinson's disease and the drugs have simply accelerated the clinical manifestations. Gibberd and Simmonds 6 observed that Far East prisoners of war were at increased risk of parkinsonism many years after their imprisonment although they could not incriminate an etiological factor.

The fact that all of the drugs used by these patients are in common use and are not widely known to produce parkinsonis $m$ does not mean they are innocuous substances. Some patients develop parkinsonism after small amounts of phenothiazines while others do not however large the dose. Some patients quickly reverse their drug induced parkinsonism when neuroleptics are stopped, others take 18 months to lose all abnormal signs and some never do. The two patients who have done least well on antiparkinsonism medication have continued with their self-administered medications.

\section{R.T. Ross \\ Health Sciences Centre Winnipeg. Manitoba}

I. Klawans HL. The Pharmacology of Parkinsonism. Diseases of the Nervous System 1968; 29(12) 805-816.

2. Thach BT, Chase TN, Bosma JF. Oral facial dyskinesia associated with prolonged use of antihistaminic decongestants. $N$ Eng $J$ Med 1975; 293: 486-487.

3. Gilman AG, Goodman LS, Gilman A. The Pharmacological Basis of Therapeutics, 6th Edition, MacMillan, New York 1980, p. 555.

4. Gilman AG, Goodman LS, Rall TW, Murad F. The Pharmacological Basis of Therapeutics, 7th edition, MacMillian. New York 1985, p. 156.

5. Spector S, Gordon R, Sjoerdsma A, Udenfriend S. End-produci inhibition of tyrosine hydroxylase as a possible mechanism of regulation of norepinephrine synthesis. Mol Pharmcol 1967: 3: 549-555.

6. Gibberd FB, Simmonds JP. Neurological disease in ex-Far East prisoners of war. Lancet 1980; ii: 135-137. 